\title{
Compactação do solo: causas e efeitos
}

\section{Soil compacting: causes and effects}

\author{
Alfredo Richart ${ }^{1}$; João Tavares Filho ${ }^{2 *}$; Osmar Rodrigues Brito ${ }^{2}$; \\ Rafael Fuentes Llanillo ${ }^{3}$; Rogério Ferreira ${ }^{4}$
}

\begin{abstract}
Resumo
Os solos agrícolas vêm sofrendo grandes perturbações, sendo a compactação apontada como a principal causa destas mudanças em virtude do tráfego de tratores e máquinas agrícolas em condições inadequadas de manejo. A presente revisão teve como objetivo discutir as causas e os efeitos da compactação sobre as propriedades físicas do solo, considerando as práticas de manejo. A extensão e a intensidade da compactação do solo vão depender da pressão exercida pelos pontos de apoio das máquinas e equipamentos, das suas cargas, do número de vezes que trafegam no terreno, da textura e da agregação do solo. As modificações que podem ocorrer nas propriedades físicas do solo vão desde aumento na densidade do solo, aumento da resistência do solo à penetração das raízes, redução da macroporosidade, conseqüentemente, menor condutividade e menor acúmulo de água, comprometendo desta forma a infiltração de água e a penetração das raízes no perfil do solo, que se torna mais suscetível à erosão. Com a adoção de algumas técnicas de manejo por parte dos agricultores poderão ser minimizados os efeitos da compactação do solo sobre suas propriedades físicas, melhorando assim o ambiente para desenvolvimento do sistema de raízes das culturas.
\end{abstract}

Palavras-chave: Tráfego de máquinas, manejo do solo, propriedades físicas, compressibilidade do solo, resistência à penetração

\begin{abstract}
The agricultural soils have been suffering great commotions and the compacting is pointed as the main cause of these changes due to the tractors and agricultural machines traffic in inadequate conditions of management. The present review had as purpose to discuss the causes and the effects of the compacting on the physic properties of the soil, considering the management. The extension and the intensity of the soil compacting will depend on the pression exerced by the help points from machines and equipments, their weight, the number of times that they traffic on the land, the texture and the aggregation of the soil. The changes that can happen in the physics properties of the soil vary since the increase in the soil bulk density, the increase of the soil resistance to the penetration of the roots, reduction of the macroporosity, consequently, less conductivity and less accumulate water, damaging the water infiltration and the penetration of the roots in the soil profile, that become more susceptible to erosion. With the adaptation of some management techniques from the farmers, the effects of soil compacting on its physics properties can be minimized, improving the development of the system of crop roots.

Key words: Machine traffic, soil management, physical properties, soil compressibility, resistance to the penetration
\end{abstract}

1 Engenheiro Agrônomo, doutorando do Programa de Pós Graduação em Agronomia da Universidade Estadual de Londrina

2 Professor do Departamento de Agronomia da Universidade Estadual de Londrina, C.P. 6001, CEP: 86051-990, Londrina, PR. email: tavares@uel.br

3 Doutorando do Programa de Pós Graduação em Agronomia da Universidade Estadual de Londrina.

4 Mestrando do Programa de Pós Graduação em Agronomia da Universidade Estadual de Londrina.

* Autor para correspondência.

Recebido para publicação 02/12/04 Aprovado em 27/07/05 


\section{Introdução}

A introdução de sistemas agrícolas em substituição às florestas causa um desequilíbrio no ecossistema em que a retirada da cobertura vegetal original e a implantação de culturas, aliadas às práticas de manejo inadequadas, promovem o rompimento do equilíbrio entre o solo e o meio, modificando desta forma, suas propriedades químicas, físicas e biológicas, limitando sua utilização agrícola. Estas alterações ocorrem na medida em que os ecossistemas naturais vão sendo substituídos por atividades voltadas para fins industriais ou para produção de alimentos (GODEFROY; JACQUIN, 1975; CENTURION; CARDOSO; NATALE, 2001). De modo geral, o solo mantido em estado natural, sob vegetação nativa, apresenta características físicas adequadas ao desenvolvimento normal das plantas (ANDREOLA; COSTA; OLSZEVSKI, 2000). Nessas condições, o volume de solo explorado pelas raízes é relativamente grande. À medida que o solo vai sendo submetido ao uso agrícola, as propriedades físicas sofrem alterações, geralmente desfavoráveis ao desenvolvimento vegetal (SPERA et al., 2004).

Algumas práticas de manejo do solo e das culturas provocam alterações nas propriedades físicas do solo, as quais podem ser permanentes ou temporárias. Assim, o interesse em avaliar a qualidade física do solo tem sido incrementado por considerá-lo como um componente fundamental na manutenção e/ou sustentabilidade dos sistemas de produção agrícola (LIMA, 2004).

De acordo com Stenberg (1999) e Schoenholtz, Van Miegroet e Burger (2000), os indicadores da qualidade física do solo deveriam abranger os atributos físicos, químicos e biológicos do solo; incorporar a variabilidade das propriedades; ser sensíveis a variações a longo prazo provocadas pelas alterações sazonais; ser mensuráveis precisamente através de uma ampla variedade de classes e condições de solos; ser simples de medir; ter um baixo custo e ser adaptáveis para diversos sistemas. Singer e Ewing (2000) e Imhoff (2002) sugerem a utilização de indicadores da qualidade física do solo que incluam os atributos físicos que influenciam diretamente a produção das culturas como a magnitude com a qual a matriz do solo resiste à deformação; a capacidade do solo em fornecer adequada aeração e quantidade de água para o crescimento e expansão do sistema radicular.

Conforme Topp et al. (1997), Schoenholtz, Van Miegroet e Burger (2000) e Singer e Ewing (2000), os atributos mais amplamente utilizados como indicadores de qualidade física do solo são aqueles que levam em conta a profundidade efetiva de enraizamento, a porosidade total e a distribuição e tamanho dos poros, a distribuição do tamanho das partículas, a densidade do solo, a resistência do solo à penetração das raízes, o intervalo hídrico ótimo, 0 índice de compressão e a estabilidade dos agregados.

Os impactos do uso e manejo na qualidade física do solo têm sido quantificados, utilizando-se diferentes propriedades físicas relacionadas com a forma e com a estabilidade estrutural do solo, tais como: compactação do solo (HORN; LEBERT, 1994; HAKANSSON; VOORHEES; RILEY, 1988), densidade (DE MARIA; CASTRO; DIAS, 1999; STONE; SILVEIRA, 2001), resistência do solo à penetração das raízes (TORMENA; ROLOFF, 1996; ROSOLEM et al., 1999; Beutler et al., 2001), estrutura (Ribeiro, 1999), porosidade total, tamanho e continuidade dos poros (BEUTLER et al., 2001; OLIVEIRA et al., 2001; SERVADIO et al., 2001), adsorção e absorção de nutrientes, infiltração e redistribuição de água, trocas gasosas e desenvolvimento do sistema radicular (DÜRR; AUBERTOT, 2000; ARVIDSSON, 2001; ISHAQ et al., 2001). As modificações nestas propriedades ocasionadas pelo manejo inadequado resultam em decréscimo de produção (RADFORD et al., 2001; DAUDA; SAMARI, 2002), aumento da suscetibilidade do solo a erosão e aumento da potência necessária para o preparo do solo (CANILLAS; SALOKHE, 2002). 
Assim, a presente revisão bibliográfica objetiva apresentar as causas e os efeitos da compactação sobre as propriedades físicas do solo, levando em consideração as práticas de manejo.

\section{Compactação do Solo}

O termo compactação do solo refere-se ao processo que descreve o decréscimo de volume de solos não saturados quando uma determinada pressão externa é aplicada, a qual pode ser causada pelo tráfego de máquinas agrícolas, equipamentos de transporte ou animais (LIMA, 2004). Para a Pedologia, a compactação do solo é definida como uma alteração no arranjo de suas partículas constituintes do solo (CAMARGO; ALLEONI, 1997).

Alakukku e Elomen (1994) afirmam que a compactação do solo tem se destacado em nível mundial como sendo um dos fatores limitantes da qualidade física das terras agrícolas, prejudicando a obtenção de maiores índices de produtividade. Canillas e Salokhe (2002) apontam a compactação dos solos como sendo um dos principais causadores da degradação dos solos agrícolas.

Atualmente, no Brasil há uma tendência de se avaliar a susceptibilidade do solo à compactação causada pelo tráfego de máquinas agrícolas conjuntamente com o momento ideal para executar as operações mecanizadas no campo, por considerar racional o uso de medidas preditivas e preventivas da compactação, o que minimizaria os problemas de degradação dos solos agrícolas (KONDO; DIAS JUNIOR, 1999; SILVA; REINERT; REICHERT, 2000a).

Em solos compactados, o desenvolvimento das plantas é menor e isto tem sido atribuído ao impedimento mecânico ao crescimento radicular, o qual resulta em menor volume de solo explorado, menor absorção de água e nutrientes e, conseqüentemente, menor produção das culturas (VIEIRA; MUZILLI, 1984; TORMENA; SILVA; LIBARDI, 1998; MEROTTO; MUNDSTOCK, 1999; GUIMARÃES; STONE; MOREIRA, 2002).
Segundo Smucker e Erickson (1989), a compactação do solo pode ter efeitos benéficos ou adversos. Os efeitos benéficos têm sido atribuídos à melhoria do contato solo-semente e ao aumento da disponibilidade de água em anos secos (CAMARGO, 1983; RAGHAVAN; MICKYES, 1983). Por outro lado, a compactação excessiva pode limitar a adsorção e/ou absorção de nutrientes, infiltração e redistribuição de água, trocas gasosas e desenvolvimento do sistema radicular, resultando em decréscimo da produção, aumento da erosão e da potência necessária para o preparo do solo (BICKI; SIEMENS, 1991; SOANE, 1990).

O processo de compactação depende de fatores externos e internos (LEBERT; HORN, 1991; DIAS JUNIOR et al., 1999). Os fatores externos são caracterizados pelo tipo, intensidade e freqüência de carga aplicada (HORN, 1998; RAGHAVAN; ALVO; MCKYES, 1990; LEBERT; HORN, 1991), enquanto que os fatores internos são histórico da tensão (REINERT, 1990; DIAS JUNIOR, 1994, DIAS JUNIOR et al., 1999), umidade (Soane, 1990; DIAS JUNIOR, 1994), textura (GUPTA; ALLMARAS, 1987; MCBRIDE, 1989), estrutura (DEXTER; TANNER, 1973; HORN, 1988), densidade inicial do solo (GUPTA et al., 1985; REINERT, 1990) e teor de carbono (ASSOULINE; TAVARES FILHO; TESSIER, 1997; ETANA; COMIA; HAKANSSON, 1997).

\section{Causas da Compactação do Solo}

\section{Impacto da gota de chuva}

A gota de chuva é considerada uma fonte natural de compactação, pois quando cai sobre o solo descoberto, poderão compactá-lo e desagregá-lo aos poucos. Conforme Bortolozzo e Sans (2001), para saber qual a amplitude dos efeitos causados pela gota de chuva, deve-se primeiro conhecer algumas de suas características, tais como: intensidade, diâmetro médio e a velocidade final das gotas médias. Laws (1940) e Wischmeier e Smith (1951) estudaram a relação entre estes parâmetros e constataram que 
gotas com diâmetros grandes apresentam uma velocidade final maior, e quanto maior a intensidade da chuva, maior a porcentagem de gotas grandes.

Segundo Schaefer et al. (2002), com o impacto das gotas de chuva sobre a superfície do solo, ocorre a quebra mecânica dos agregados, resultando na formação de uma camada adensada na superfície do solo, o selamento superficial. Conforme Agassi, Morin e Shainberg (1985), a formação do selamento superficial deve-se a dois mecanismos: (1) fragmentação física dos agregados do solo e seu adensamento; (2) dispersão físico-química e migração das partículas de argila para a região de 0,1 a 0,5 $\mathrm{mm}$ de profundidade, onde se alojam, obstruindo os poros. O primeiro mecanismo predomina e é determinado pela energia cinética das gotas. $\mathrm{O}$ segundo, é controlado principalmente pela concentração e composição de cátions no solo e pela aplicação de água. Os dois mecanismos atuam simultaneamente e o primeiro incrementa o segundo.

Embora o selamento superficial seja uma camada compactada de pequena espessura, ocasiona mudanças na taxa de infiltração de água no solo e, também, funciona como impedimento a emergência das plantas. Lal (1974) verificou redução de 40 e $73 \%$ na infiltração acumulada, respectivamente em uma área cultivada com milho por um ano, e em outra preparada e sem cobertura, mantida pelo mesmo período, comparadas com uma área sob floresta. Segundo o autor, as diferenças foram devidas às alterações na estrutura, sobretudo na superfície; pelo selamento ocasionado pela energia cinética das gotas de chuva.

\section{Operações de preparo do solo}

O preparo tem por objetivo melhorar as condições do solo para favorecer a germinação das sementes e o crescimento e desenvolvimento das plantas, facilitar o movimento de água e ar, controlar plantas indesejáveis e, em alguns casos, auxiliar no manejo dos resíduos culturais (LARSON; GILL, 1973).
Por outro lado, também apresenta efeitos negativos, pois o preparo reduz a rugosidade da cobertura do solo (BERTOL, 1995), pulveriza a superfície e forma camadas compactadas na subsuperfície (Dalla Rosa, 1981), além de facilitar a erosão hídrica (HERNANI et al., 1997; LINDSTROM et al., 1998), também limita o crescimento das raízes, o desenvolvimento e a produção das culturas (SILVA; REINERT; REICHERT, 2000a).

No sistema de preparo convencional do solo, a grade aradora tem sido o equipamento mais utilizado. Normalmente a grade trabalha o solo a pouca profundidade e apresenta alto rendimento de campo, porém o uso contínuo desse implemento pode levar à formação de camadas compactadas, chamadas "péde-grade" (SILVA, 1992). Os arados, tanto de disco como de aiveca são equipamentos pouco utilizados, porque requerem maior tempo e energia para a sua operação (KOCHHANN; DENARDIM, 1997; KLUTHCOUSKI et al., 2000).

Segundo Hakansson, Voorhees e Riley (1988), o sistema de preparo convencional do solo ocasiona compactação subsuperficial em virtude da mobilização e descompactação mecânica da camada mobilizada, ao mesmo tempo em que a carga aplicada apresenta efeito acumulativo em subsuperfície ao longo dos anos. Saxon, McCcool e KENNY (1988) estudaram a influência das práticas culturais na compactação de solos de textura franco-siltosa mecanizados superficialmente todos os anos e que passavam por ciclos de congelamento. Verificaram que as práticas culturais modificam a densidade do solo e, conseqüentemente, a infiltração de água, especialmente nas áreas com intensa mecanização, causando impacto negativo nas condições físicas e nos processos químicos e biológicos do solo.

\section{Tráfego de máquinas agrícolas}

Esta é a principal causa da compactação do solo, que foi intensificada pela modernização da 
agricultura, com o aumento do peso das máquinas e equipamentos e da intensidade de uso do solo. Esse processo não foi acompanhado por um aumento proporcional do tamanho e largura dos pneus, resultando em significativas alterações nas propriedades físicas do solo.

Conforme Silva et al. (2003), fazendo uma análise dos objetivos e da forma como são realizados trabalhos que visam avaliar a influência do tráfego de máquinas nos solos brasileiros, percebe-se que a maioria deles é feita em uma condição estática e quase sempre voltada à obtenção de um resultado qualitativo e comparativo, cujas variáveis normalmente avaliadas são a densidade do solo e a porosidade. Neste caso, três ponderações podem ser feitas: que as operações agrícolas ocorrem de forma dinâmica, que a densidade do solo e a porosidade são fortemente dependentes do manejo e, que quase sempre são desconsideradas informações, tais como o tipo de pneu, pressão de inflação, pressão de contato, umidade do solo, profundidade de trabalho e especificações técnicas dos implementos utilizados.

Todavia, diferentemente da pesquisa nacional, em outros países os estudos que envolvem a influência do tráfego agrícola no comportamento da estrutura já estão mais avançados. Estes estudos vão desde a quantificação e distribuição da tensão aplicada no solo até os deslocamentos, vertical e horizontal, medidos in situ a partir de transdutores (OLSON, 1994; HORN, 1994, 1998; WIERMANN et al., 1999, 2000), levando em consideração a relação tensão de deformação do solo, a qual tem se mostrado necessária para compreender o processo de compactação dos solos agrícolas (KOOLEN, 1994; HORN, 1998).

HORN (1995) afirma que não somente a pressão estática causa compactação, mas também forças dinâmicas causadas pela vibração do trator arrastando implementos e pelo patinamento. Investigações recentes têm mostrado o efeito do tráfego contínuo e inadequado de máquinas e implementos sobre os atributos físicos e mecânicos dos solos agrícolas (JORGE, 1986; NOVAK et al., 1992; MIRANDA, 2001; CASTRO NETO, 2001). A aplicação de cargas dinâmicas por rodados e implementos agrícolas no solo produz tensões na interface solo/pneu e solo/implemento em superfície e em profundidade, respectivamente. Essas tensões compactam as diferentes camadas do solo (HORN; LEBERT, 1994) e, caso este carregamento dinâmico exceda a resistência interna do solo, mudanças nas propriedades físicas das camadas mais profundas ocorrerão (HORN, 1988).

Os pneus usualmente utilizados nos tratores e colhedoras comercializadas no Brasil possuem a parte lateral do pneu rígida, sendo chamados de pneus de banda diagonal. Essa rigidez impede que o pneu se molde ao solo de acordo com as irregularidades do terreno e, por isso, a sua área de contato fica reduzida, aumentando a pressão na superfície do solo (SILVA; CURI; BLANCANEAUX, 2000).

O aumento progressivo das cargas externas, combinado com a insuflagem inadequada dos rodados, contribui para a degradação das camadas do solo em profundidade, em decorrência do deslizamento causado, geralmente, pelo aumento do cisalhamento na superfície, o que implica no rearranjamento das partículas do solo, e, conseqüentemente, alterações na estrutura. A disponibilidade de água e nutrientes é comprometida pela alteração da estrutura do solo, tendo como conseqüência um declínio da produtividade (WIERMANN et al., 1999, 2000).

Um outro aspecto a ser considerado diz respeito à persistência da compactação do solo causada pelo tráfego de máquinas (SMITH; STONEMAN; MALCOLM, 1969; BLACK; NELSON; ALLMARAS, 1976; VOORHEES, 1977; VOORHEES; SENST; NELSON, 1978; POLLARD; ELLIOTT, 1978; LOGSDON et al., 1992). Alguns estudos mostram que os efeitos da compactação da superfície do solo são apenas temporariamente prejudiciais e a compactação da camada arável tende a ser aliviada pelo preparo do 
solo nos cultivos sucessivos (DIAS JUNIOR; PIERCE, 1996). Já a compactação do subsolo pode ser aliviada mediante a subsolagem e tende a ser de caráter permanente devido às peculiaridades da subsolagem.

De acordo com Lowey e Schuler (1994), Alakukku e Elomen (1994) e Ball et al. (1997), a densidade do solo é significativamente elevada após o tráfego de máquinas agrícolas, com redução da macroporosidade e conseqüente diminuição da condutividade hidráulica. Way et al. (1995) verificaram aumento significativo da densidade do solo abaixo da linha de tráfego, sendo esse aumento tanto maior quanto maior o número de carregamentos. Wood et al. (1993) constataram que, antes do preparo, o tráfego de quatro passadas de uma carreta graneleira provocou decréscimos de até $50 \%$ na porosidade e permeabilidade nas profundidades de 0,20 a $0,40 \mathrm{~m}$, quando comparados com o efeito provocado por uma única passada. Constatações semelhantes foram feitas por Novak et al. (1992), Bailey et al. (1993), Horn (1994) e Way et al. (1995).

Segundo Trein, Levien e Souza (2005), uma solução para diminuir ou evitar a compactação do solo pelo tráfego de máquinas seria a adoção de um sistema de tráfego controlado, ou seja, separar as zonas de tráfego das zonas em que há crescimento das plantas, concentrando a passagem de pneus em linhas delimitadas, assim, uma área menor seria atingida, embora mais intensamente. Os autores enfatizam que o sistema de tráfego controlado funciona bem com culturas que são estabelecidas em linha. Trabalhos realizados na Austrália e nos Estados Unidos mostram que, enquanto culturas estabelecidas em preparo convencional têm até $86 \%$ da área trafegada, em semeadura direta, apenas $46 \%$ é atingida. Também mostram que, se for utilizado controle do tráfego, apenas $17 \%$ da área é atingida pelos pneus, resultando em aumentos de produtividade da ordem de 9 a 16\%. Os mesmos autores chamam a atenção para um componente fundamental para que se tenha sucesso com a adoção deste sistema, que é o uso dos implementos com as mesmas larguras ou em larguras múltiplas. Portanto, deve-se tentar diminuir as áreas trafegadas pelo ajuste das bitolas de todas as máquinas empregadas na produção da cultura. Como exemplo, pode-se citar o caso de um trator que opera com uma semeadora de seis linhas de semeadura espaçadas em $75 \mathrm{~cm}$. Se este trator estiver com uma bitola de $1,5 \mathrm{~m}$, e a colhedora estiver com uma bitola de $3 \mathrm{~m}$, serão atingidos $44 \%$ da área semeada. Ao aumentar a bitola do trator para a mesma da colhedora, apenas $17 \%$ da área será atingida. Assim, os benefícios obtidos a partir da adoção do tráfego controlado passam pela redução do uso de combustível, em razão da menor oposição ao avanço das máquinas, e pelo melhor rendimento da tração, em razão do tráfego sobre solo mais compactado. Isto significa, também, que o potencial de tração do solo (interface trator-solo) melhora. Outro benefício imediato é a menor demanda de energia necessária, para tracionar a semeadora, uma vez que os órgãos sulcadores estarão trabalhando em área que não é submetida ao tráfego.

Fenner (1999), fazendo um estudo de tráfego controlado em solos da Amazônia, verificou que as maiores deformações no solo ocorrem logo após a primeira passagem da máquina, sendo os efeitos das passagens subseqüentes mais reduzidos. A estimativa é que as pressões médias aplicadas aos solos pelas máquinas agrícolas se situam entre 50 e $300 \mathrm{kPa}$ (LEBERT; HORN, 1991; CARPENEDO, 1994; SILVA; REINERT; REICHERT, 2000a) e os reboques e caminhões podem exercer pressões entre 300 e 600 kPa (CARPENEDO, 1994; SILVA; REINERT; REICHERT, 2000a).

$\mathrm{Na}$ tentativa de solucionar os problemas decorrentes do preparo convencional, surgiram os preparos conservacionistas, que proporcionam menor mobilização do solo e mantêm maior proteção da superfície do solo com os resíduos culturais. O plantio direto e o cultivo mínimo são tipos de manejo conservacionista que procuram minimizar a mobilização do solo. No entanto, mesmo com a ausência de revolvimento do solo, têm sido diagnosticados problemas de compactação superficial 
do solo. Hakansson e Medvedev (1995) e Klein e Boller (1995) afirmam que a compactação em sistema de plantio direto é provocada pelo efeito cumulativo do tráfego de máquinas e acomodação natural das partículas sólidas. No plantio direto a movimentação do solo é restrita à linha de semeadura, mas a ocorrência sistemática do tráfego causa compactação na camada superficial. Portanto, a compactação em superfície no sistema de plantio direto tem motivado alguns agricultores, ainda que temporariamente, a retornar ao preparo convencional do solo, visando corrigir essa limitação (TORMENA; SILVA; LIBARDI, 1998; TORMENA; ROLOFF, 1996).

\section{Fatores Envolvidos na Compactação do Solo}

A magnitude dos efeitos do manejo sobre as propriedades físicas do solo é determinada por condições climáticas, classe de solo, sistemas de rotação de culturas utilizados, tempo de uso dos diferentes sistemas de manejo e condição de umidade do solo em que são realizadas as operações de campo (BERTOL et al., 2000).

Estudos do processo de compactação do solo têm demonstrado que diferentes classes de solos apresentam comportamentos distintos quando submetidos ao processo de compactação, devido a vários fatores, tais como: energia de compactação, textura, teor de matéria orgânica, umidade (DIAS JUNIOR, 1994; EKWUE; STONE, 1995; DIAS JUNIOR; PIERCE, 1996) e história de tensão induzida pelos processos pedogenéticos ou devido ao manejo que o solo foi submetido no passado (DIAS JUNIOR, 1994; DIAS JUNIOR; PIERCE, 1996). Portanto, o estudo da compactação em diferentes classes de solos submetidos a diferentes sistemas de manejo e com diferentes graus de umidade é de grande importância (SILVA; LIBARDI; CAMARGO, 1986).

\section{Textura do solo}

A textura do solo apresenta grande importância no processo de compactação. Quando determinada pressão externa é aplicada ao solo por máquinas, equipamentos de transporte ou animais ocorre um novo acomodamento e/ou arranjamento das partículas, diminuindo o espaço aéreo do solo, incrementando a densidade e a resistência à penetração e consequentemente, aumentando a compactação (SOANE, 1986; HORN; LEBERT, 1994).

A resistência e a resiliência do solo a determinada prática agrícola depende da textura e da mineralogia do solo (SEYBOLD; HERRICK; BREJDA, 1999). O teor e o tipo de argila também afetam o funcionamento compressivo do solo, determinando, portanto, a profundidade de transmissão e a persistência da compactação (McBRIDE; WATSON, 1990). Assim, quanto maior o teor de argila, maior a profundidade a qual a pressão é transmitida e maior a espessura da camada compactada (HORN, 1988).

Dias Junior e Miranda (2000), trabalhando com solos da região de Lavras, MG, Latossolo VermelhoAmarelo distrófico (LV), Latossolo Vermelho-Escuro distrófico (LE); Latossolo Roxo distrófico (LR), Podzólico Vermelho-Amarelo distrófico (PV) e Cambissolo distrófico (Cd), coletando amostras deformadas na profundidade de $0-30 \mathrm{~cm}$, observaram que os valores das densidades máximas atingidas pelos solos obedeceram a seguinte ordem decrescente de valores: $\mathrm{Cd}>\mathrm{LV}>\mathrm{PV}>\mathrm{LE}>\mathrm{LR}$. Esse aumento da densidade do solo máxima segue a mesma tendência da fração areia e pode ser devido à maior capacidade de empacotamento das partículas do solo devido à forma irregular dos grãos de areia. Assim, com base nos resultados do ensaio de Proctor normal, espera-se que o Cambissolo tenha problemas de compactação a umidades mais baixas do que os demais solos, enquanto o Latossolo Roxo atingirá a sua densidade máxima a maiores umidades do que os outros. Esse fato pode constituir uma vantagem em relação ao tempo disponível para a realização 
das operações motomecanizadas necessárias para o preparo do solo em condições adversas de umidade.

Resultados similares foram encontrados por Ohu, Ayotamuno e Folorunso (1987), que observaram que solos com classe textural areiafranca são mais susceptíveis à compactação do que os solos franco-arenosos, devido ao teor de areia do primeiro ser maior.

\section{Umidade do solo}

Numa mesma condição, o fator que governa a quantidade de deformação que poderá ocorrer no solo é a umidade (DIAS JUNIOR, 1994). Assim, quando os solos estão mais secos, sua capacidade de suporte de carga pode ser suficiente para agüentar as pressões aplicadas e a compactação do solo pode não ser significativa. Entretanto, sob condições de alta umidade, o solo deforma-se mais facilmente, ocorrendo a formação de camadas compactadas (SWAN; MONCRIEF; VOOHEES, 1987).

A água no solo atua como lubrificante entre as partículas, permitindo o deslocamento das mesmas. Desta forma, o movimento das partículas de solo é favorecido pelo aumento da umidade. Este processo continua até que a água sature praticamente todos os poros do solo. A partir desse momento, a cada incremento no conteúdo de água não corresponderá um incremento na densidade, visto que a água não pode ser comprimida (SMITH; JOHNSTON; LORENTS, 1997; SILVA; REINERT; REICHERT, 2000a).

Segundo Imhoff (2002), existe controvérsia entre os autores acerca do efeito do conteúdo de água sobre a susceptibilidade do solo à compactação. Para Larson e Gupta (1980) e O’Sullivan (1992) não há relação entre estes dois atributos, mas Sánchez-Girón, Andreu e Hernanz (1998) demonstraram que a suscetibilidade do solo à compactação foi fortemente correlacionada com a umidade do solo. Essas diferenças parecem estar relacionadas com o fato de que a diminuição do conteúdo de água no solo incrementa o número de contatos entre as partículas, o que por sua vez, depende diretamente da textura do solo (McNABB; BOERSMA, 1996).

No manejo do solo, tanto para os sistemas de preparo com o revolvimento do solo, como para o sistema plantio direto, em que não ocorre o revolvimento, um requisito importante a ser levando em consideração é o intervalo hídrico ótimo. Este parâmetro representa a faixa de conteúdo de água no solo definida no limite superior pela umidade do solo na capacidade de campo, ou no conteúdo de água em que a aeração do solo se torna limitante, e no limite inferior pelo conteúdo de água no ponto de murcha permanente, ou no conteúdo de água em que a resistência do solo à penetração torna-se limitante (KAY; SILVA; BALDOCK, 1997). Diversos estudos comprovaram a eficácia do intervalo hídrico ótimo como indicador de alterações nas propriedades físicas do solo em diferentes culturas e sistemas de manejo (SILVA; KAY; PERFECT, 1994; TORMENA; SILVA; LIBARDI, 1998; WU et al., 2003).

Silva et al. (2003), estudando o intervalo hídrico ótimo na cultura do feijão em Latossolo Vermelho, verificaram que no preparo reduzido do solo a cultura permaneceu três dias a mais no intervalo hídrico ótimo quando comparado ao preparo convencional e ao plantio direto; contudo, esta diferença não se refletiu na produtividade da cultura.

Dias Junior e Miranda (2000) observaram que os valores das umidades ótimas de compactação seguiram uma ordem crescente de valores $\mathrm{Cd}<\mathrm{LV}$ $<$ PV $<$ LE $<$ LR, seguindo a mesma tendência para o teor de argila $(\mathrm{Cd}<\mathrm{PV}<\mathrm{LV}<\mathrm{LE}=\mathrm{LR})$. Portanto, o aumento da umidade ótima de compactação com o aumento do teor de argila está relacionado com sua capacidade de adsorção de água (SILVA; LIBARDI; CAMARGO, 1986; EKWUE; STONE, 1997).

Em áreas que possuem um período sazonal pequeno para o crescimento das plantas ou em sistemas de manejo com três culturas por ano, as operações de preparo do solo são realizadas assim 
que os solos são considerados trafegáveis. Entretanto, nessas condições, eles muitas vezes ainda estão úmidos demais e esse tráfego pode resultar em compactação adicional do solo (HAKANSSON; VOORHEES; RILEY, 1988). Assim, o ideal é que o intervalo hídrico ótimo de cada classe de solo seja respeitado para evitar problemas com a compactação.

\section{Matéria orgânica}

O teor de matéria orgânica (M.O.) é caracterizado como um dos fatores responsáveis pela manutenção das condições físicas do solo e também influencia a resposta dos solos à compactação (ASSOULINE; TAVARES FILHO; TESSIER, 1997; DIAS JUNIOR et al., 1999). O uso de coberturas mortas ou fertilizantes orgânicos que venham a promover a manutenção e o aumento de M.O. no solo são um importante aliado contra o processo de compactação (CAMARGO; ALLEONI, 1997).

Segundo Soane (1990), existem vários mecanismos pelos quais a M.O. influencia a capacidade dos solos em resistir às forças de compactação: a) força de união entre partículas e entre agregados, b) elasticidade, c) efeito de diluição, d) efeito de cargas elétricas, e) efeito na fricção. Dentre estes mecanismos, a estabilidade dos agregados é o fator determinante na susceptibilidade do solo à compactação. Conforme explicam Costa et al. (2004), no solo ocorre um efeito sinérgico entre o aumento dos estoques de M.O. e os processos que levam ao aumento da estabilidade dos agregados, ou seja, pode-se estabelecer uma relação causa-efeito entre agregação e a M.O, na qual o aumento da estabilidade de agregados do solo é ao mesmo tempo uma causa e uma conseqüência dos maiores estoques de matéria orgânica do solo (SIX; ELLIOT; PAUSTIAN, 1999). Neste sentido, Zhang, Hartge e Ringe (1997) e McBride e Bober (1989) afirmam que a susceptibilidade do solo à compactação decresce com o incremento no teor de carbono orgânico no solo devido à redução da faixa de umidade na qual o solo exibe propriedades plásticas. Portanto, os autores apontam que um bom aporte de matéria orgânica ao solo poderá diminuir os efeitos da compactação do solo.

Perin et al. (2003), trabalhando com dois solos, um Latossolo Vermelho distrófico (LVd) de textura argilosa e um Latossolo Vermelho distrófico (LVd) de textura média, localizados na região do Planalto Médio do Rio Grande do Sul, efetuaram amostragens em três perfis por classe de tempo de uso no LVd textura argilosa: tempo zero $(\mathrm{T} 0)=$ mata; tempo um $(\mathrm{T} 1)=8-18$ anos de uso agrícola; tempo dois $(\mathrm{T} 2)=$ 18-33 anos de uso; tempo três (T3) $=>33$ anos de uso. No LVd textura média, amostrou-se o solo em dois perfis por classe de tempo de uso: $\mathrm{T} 0=$ campo nativo; $\mathrm{T} 1=8-22$ anos de uso; $\mathrm{T} 2=22-33$ anos de uso, $\mathrm{T} 3=>33$ anos de uso. Em cada perfil, coletaram-se amostras nos horizontes A1/Ap, AB, $\mathrm{BA}$ e Bw com abertura de trincheira $(0,50 \times 0,50 \mathrm{x}$ $0,50 \mathrm{~m}$ ) e, a partir de $0,50 \mathrm{~m}$, com trado, até uma profundidade mínima de $1,0 \mathrm{~m}$. Os autores constataram declínio no teor de matéria orgânica com o tempo de uso agrícola, principalmente no horizonte superficial. Originalmente, o solo apresentava 3,0 dag $\mathrm{kg}^{-1}$ de M.O. no horizonte superficial, mas, nos perfis com mais de 33 anos de uso agrícola, o teor foi reduzido para 2,3 dag $\mathrm{kg}^{-1}$. Porém, como as áreas estudadas encontram-se sob sistema plantio direto, essa tendência de redução no teor de M.O. poderá ser revertida.

Bayer (1996) afirma que o uso agrícola tende à redução no teor de M.O. do solo pelo aumento na taxa de decomposição, especialmente quando o preparo do solo é feito com revolvimento, causando um balanço negativo entre adição e perda de carbono.

\section{Densidade do solo}

A presença de uma estrutura maciça e adensada nas camadas superficial e subsuperficial são comuns na maioria dos solos cultivados intensivamente, com valores de densidade do solo mais elevados e, aeração, penetração e a proliferação de raízes 
também são prejudicadas. Assim, a densidade pode variar consideravelmente, dependendo da textura, dos teores de matéria orgânica do solo (Curtis e Post, 1964) e da freqüência de cultivo (HAJABBASI; JALALIAN; KARIMZADEH, 1997).

Para solucionar o problema de altos valores de densidade, alguns agricultores têm utilizado a subsolagem nas operações de preparo do solo para a semeadura, precedendo a outras operações convencionalmente utilizadas com a finalidade de aliviar a compactação (CASTRO FILHO et al., 1993).

Não existe consenso entre os autores sobre o nível crítico da densidade do solo, ou seja, o valor acima do qual o solo é considerado compactado. Torres e Saraiva (1999) afirmam que a densidade varia de acordo com as características do solo, sendo que em solos argilosos varia de 1,0 a $1,45 \mathrm{Mg} \mathrm{m}^{-3}$ para condições de mata e muito compactados, respectivamente e para solos arenosos apresentam densidades variáveis entre 1,25 a 1,70 $\mathrm{Mg} \mathrm{m}^{-3}$ respectivamente. Camargo e Alleoni (1997) consideram crítico o valor de $1,55 \mathrm{Mg} \mathrm{m}^{-3}$ em solos franco-argilosos a argilosos. De Maria, Castro e Dias (1999) constataram que em Latossolo Roxo, ocorre restrição ao desenvolvimento de raízes acima de $1,2 \mathrm{Mg} \mathrm{m}^{-3}$.

De Jong-Hughes et al. (2001) afirmam que um solo ligeiramente comprimido pode apressar a taxa de germinação das sementes, porque promove um bom contato entre a semente e solo. Além disso, uma compactação moderada pode reduzir a perda de água do solo por evaporação e, conseqüentemente, impedir que o solo em torno da semente seque rapidamente. Um solo de textura média, com densidade de $1,2 \mathrm{Mg}$ $\mathrm{m}^{-3}$ é geralmente favorável para o crescimento da raiz, sendo que esta densidade do solo corresponde às condições do solo após uma operação secundária de preparo (utilização da grade niveladora, a qual diminui a rugosidade da superfície do solo). Entretanto, as raízes que crescem através de um solo com textura média e com uma densidade igual ou maior que $1,2 \mathrm{Mg} \mathrm{m}^{-3}$, provavelmente não terão um grau elevado de ramificação ou formação de raízes secundárias. Neste caso, uma compactação moderada pode aumentar a ramificação e a formação de raízes secundárias, permitindo que as raízes explorem mais o solo para absorção de nutrientes, em especial os nutrientes de pouca mobilidade no solo, como o fósforo.

\section{Porosidade do solo}

A porosidade do solo é uma propriedade física do solo que sofre grandes alterações com a compactação. Pesquisas realizadas em várias regiões apontam alterações significativas com a compactação no decréscimo da porosidade, da continuidade do número e tamanho dos poros e da difusão de gases, com reduções significativas principalmente no volume dos macroporos (NOVAK et al., 1992; TAYLOR; BRAR, 1991; HILLEL, 1982).

Com relação a distribuição e tamanho dos poros, a microporosidade é responsável pela capacidade de retenção de água e solutos no solo, enquanto que a macroporosidade influencia diretamente a capacidade de infiltração, a drenabilidade do solo e sua capacidade de aeração (HILLEL, 1998).

Segundo Hatano et al. (1988), existe uma estreita relação entre porosidade do solo e crescimento radicular. Vomocil e Flocker (1966) sugerem uma macroporosidade mínima de $0,10 \mathrm{~m}^{3}$ $\mathrm{m}^{-3}$ para o crescimento e o desenvolvimento satisfatórios das plantas.

Abreu (2000) afirma que poros formados pela ação das raízes no solo são mais estáveis, pois a decomposição por microrganismos gera materiais que atuam como cimentantes nas paredes dos poros, proporcionando maior durabilidade, se comparados àqueles formados por implementos mecânicos.

No sistema plantio direto, em geral, os solos apresentam após três a quatro anos, maiores valores de densidade e microporosidade na camada superficial, e menores valores de macroporosidade e porosidade total, quando comparado com o preparo convencional. Isto ocorre, sobretudo pelo 
arranjamento natural do solo não mobilizado, e pela pressão provocada pelo trânsito de máquinas e implementos agrícolas, em particular quando realizado em solos argilosos e com teores elevados de umidade (SILVEIRA; STONE, 2003).

\section{Estrutura do solo}

Segundo Resende et al. (1995), a estrutura do solo pode ser definida como sendo o arranjo das partículas, ou seja, das frações argila, silte e areia. $\mathrm{Na}$ avaliação da estrutura do solo, o fator primordial a ser considerado diz respeito à estabilidade dos agregados, a qual é dependente das forças que ligam as partículas e também, da natureza e magnitude das forças desagregantes aplicadas nesta avaliação (BEARE; BRUCE, 1993). Fuller e Goh (1992) afirmam que existem vários métodos para avaliação da estabilidade de agregados, dentre eles métodos como o peneiramento úmido de Yoder (1936) e suas modificações (KEMPER; CHEPIL, 1965; Oliveira et al., 1983; Kemper e Rosenau, 1986), peneiramento úmido e turbidimetria (POJASOK; KAY, 1990), resistência do agregado ao impacto de gotas de chuva (McCALLA, 1944; MAZURAK; MOSHER, 1968; BRUCE-OKINE; LAL, 1975; FARRES; COUSEN, 1985; SILVA et al., 1995) e, mais recentemente, métodos envolvendo energia ultra-sônica, que permitem a quantificação da energia necessária para dispersão dos agregados (NORTH, 1976; GREGORICH; KACHANOSKI; VORONEY, 1988; RAINE; SO, 1993).

Albuquerque et al. (1995) afirmam que dentre as propriedades físicas do solo, a estrutura é uma das propriedades mais sensíveis ao manejo e sua qualidade pode ser analisada segundo variáveis relacionadas com sua forma e com sua estabilidade (CAMPOS et al., 1995). Um dos efeitos da compactação é a modificação da estrutura do solo, podendo limitar a adsorção e a absorção de nutrientes, a infiltração e a distribuição de água, resultando em problemas no estabelecimento e no crescimento das raízes (FLOWERS; LAL, 1998; KLEIN; LIBARDI; SILVA, 1998; IMHOFF, 2002).
Os diferentes sistemas de manejo de solos têm por finalidade criar condições favoráveis ao desenvolvimento das culturas. Todavia, o desrespeito às condições mais favoráveis para o preparo do solo e o uso de máquinas cada vez maiores e pesadas para essas operações pode levar a modificações na estrutura do solo, causando-lhe maior ou menor compactação, que poderá interferir na infiltração de água no solo, na condutividade hidráulica do solo saturado e no desenvolvimento radicular das culturas e, conseqüentemente, reduzir sua produtividade (DERPSCH et al., 1991; TAVARES FILHO; TESSIER, 1998; DE MARIA et al., 1999).

Barbosa, Tavares Filho e Fonseca. (2002) verificaram que a estrutura do solo é modificada em função da compactação, sendo que os macroagregados são destruídos e o solo apresenta estrutura degradada, podendo impedir o crescimento de raízes e diminuir o volume de solo explorado pelo sistema radicular.

Geralmente, as práticas de manejo têm maior impacto sobre as propriedades físicas de solos arenosos do que de solos argilosos. Silva e Mielniczuk (1997) verificaram redução do diâmetro médio ponderado (DMP) dos agregados de $71 \%$ num Argissolo Vermelho (220 $\mathrm{g} \mathrm{kg}^{-1}$ de argila) e de $47 \%$ num Latossolo Roxo (680 $\mathrm{g} \mathrm{kg}^{-1}$ argila), quando passaram de uma condição de campo nativo para preparo convencional com culturas anuais, submetidos a aração e gradagem. Por outro lado, os mesmos autores verificaram aumento da estabilidade de agregados em ambos os solos quando submetidos ao sistema plantio direto. O DMP dos agregados passou de 0,61 mm, no Argissolo, e de 1,76 mm, no Latossolo, em preparo convencional, para 0,91 e 1,90 $\mathrm{mm}$, respectivamente, em plantio direto. Em termos relativos, o aumento ocorrido na estabilidade de agregados do solo em plantio direto foi de 49 e $8 \%$, respectivamente, no Argissolo franco-arenoso e no Latossolo argiloso.

Segundo Denardin e Kochhann (1997), as mobilizações intensivas do solo, principalmente no 
sistema convencional, sob condições inadequadas de umidade e de cobertura vegetal, modificam adversamente a estrutura do solo, afetando basicamente as relações entre as fases: sólida, líquida e gasosa. Desta forma, transformam a camada arável, que passa a ter a superficial pulverizada e a subsuperficial compactada. Entretanto, o sistema plantio direto é um sistema de produção agrícola em que a semeadura das culturas é feita sem preparo do solo, mantendo os restos culturais dos cultivos anteriores na superfície. Esse sistema de manejo é eficaz na proteção da superfície do solo contra agentes erosivos, mas como não há revolvimento do solo, pode ocorrer a formação de camadas compactadas na distribuição das pressões exercidas na superfície do solo pelas máquinas/implementos ou casco de animais, em áreas de integração lavourapecuária (CRUZ et al., 2003).

A adoção de sistemas conservacionistas de manejo do solo têm sido apresentado como uma opção para assegurar a sustentabilidade do uso agrícola dos solos, pois com a utilização de práticas de manejo que mantém a proteção do solo através do contínuo aporte de resíduos orgânicos é fundamental para a manutenção da estrutura do solo (Silva et al., 2000a).

\section{Compressibilidade do solo}

O termo compressibilidade indica a resistência do solo ao decréscimo de volume quando submetido a uma carga mecânica, sendo definido como a facilidade com que o solo diminui o volume quando uma determinada pressão é aplicada (GUPTA; ALLMARAS, 1987; HORN; LEBERT, 1994). Esta propriedade é uma das maneiras utilizadas para avaliar a compactação do solo.

Pesquisas sobre a compressibilidade têm surgido com o intuito de avaliar de forma detalhada o processo de compressão do solo (IMHOFF, 2002). Desta forma, a compressibilidade é a expressão quantitativa da resposta do solo à compactação. A compressibilidade depende primariamente das propriedades físico-mecânicas do solo (ETANA;
COMIA; HAKANSSON, 1997) e, em menor grau, do nível e do modo de aplicação da energia utilizada para exercer a compactação (FAUNE, 1981).

Algumas destas propriedades físico-mecânicas relativas ao comportamento compressivo do solo são obtidas com a curva de compressão (Dias Junior e Pierce, 1996), representada graficamente pela relação entre o logaritmo da pressão aplicada e a densidade do solo ou índice de vazios (HOLTZ; KOVACS, 1981). Como exemplos dessas propriedades, citam-se o índice de compressão e a pressão de preconsolidação (DIAS JUNIOR, 1994; DIAS JUNIOR; PIERCE, 1996; KONDO; DIAS JUNIOR, 1999; SILVA; REINERT; REICHERT, 2000a; SILVA et al., 2001). O índice de compressão refere-se ao processo que descreve o decréscimo de volume do solo quando alguma pressão externa é aplicada (KOOLEN, 1994), enquanto que a pressão de preconsolidação é uma estimativa da capacidade de suporte de carga do solo (LEBERT; HORN, 1991; DIAS JUNIOR; PIERCE, 1996).

Oliveira et al. (2003), objetivando estudar o comportamento compressivo de um Latossolo Vermelho argiloso da região do cerrado, submetido a diferentes sistemas de uso ou manejo e diferentes tensões de água no solo, verificaram que na profundidade de $0-5 \mathrm{~cm}$, os índices de compressão não foram diferentes, independentemente da tensão de água no solo (faixa de tensão de 6 e $1.500 \mathrm{kPa}$ ). Na reta de compressão do solo virgem, a variação da densidade do solo foi a mesma para qualquer tensão de água no solo. No entanto, os valores da densidade do solo final foram maiores à medida que aumentou o conteúdo de água no solo. Estes resultados revelam uma tendência à maior deformação do solo sob cerrado para conteúdo de água mais elevado, o que está relacionado com sua menor densidade e com o maior espaço poroso disponível à deformação.

Dias Junior e Miranda (2000) observaram que, independentemente da classe de solo, à medida que a umidade gravimétrica aumentou, a densidade do 
solo também aumentou até atingir um valor máximo e, a seguir, diminuiu devido à baixa compressibilidade da água. No ponto de máximo, ou seja, no vértice da parábola, obteve-se o valor da densidade do solo máxima e da umidade ótima de compactação.

Segundo Larson e Gupta (1980), com a aplicação de pressões maiores do que a pressão de preconsolidação observa-se que alterações significativas ocorreram na estrutura do solo, evidenciadas pelas mudanças significativas dos valores de densidade do solo. Este fato pode ser explicado pelo aumento do número de contatos entre cada agregado com o aumento da pressão aplicada, até que os agregados se rompem e o solo adquire uma estrutura maciça.

\section{Modelagem da compactação do solo}

A modelagem tem apresentado grande potencialidade para o entendimento do processo de compressão dos solos. Dias Junior e Pierce (1995) desenvolveram um modelo não linear que permite determinar a pressão máxima que o solo pode suportar sem sofrer compactação adicional, baseando-se nos diferentes teores de umidade de solos de regiões temperadas.

No Brasil, Kondo (1998), utilizando o modelo desenvolvido por Dias Junior e Pierce (1995) em Latossolos da região de Lavras, demonstrou que a compressibilidade do solo é influenciada pelo sistema de manejo.

Em estudos da capacidade de suporte ou compressibilidade do solo, Dias Junior (1994) sugere a utilização de modelos de compressibilidade com base na pressão de preconsolidação, que predizem a máxima pressão que um solo pode suportar a diferentes umidades, sem causar compactação adicional, fornecendo, portanto, informações para a prevenção da compactação. Estes estudos têm mostrado que quando ensaios de compressão uniaxial são realizados em solos que não sofreram pressão prévia ou secagem e umedecimento, a relação entre a pressão aplicada e a densidade do solo é linear, e qualquer pressão aplicada provocará deformações ou não (DIAS JUNIOR; PIERCE, 1996). Entretanto, quando os ensaios são realizados em solos que já tenham uma história de manejo, as deformações resultantes poderão ser recuperáveis e nãorecuperáveis (STONE; LARSON, 1980; GUPTA; HADAS; SCHAFER, 1989; LEBERT; HORN, 1991; DIAS JUNIOR; PIERCE, 1996). É na região da curva de compressão secundária que o solo deve ser cultivado ou trafegado, para que não ocorra compactação adicional, pois é este o componente da curva de compressão que reflete a história de manejo do solo (DIAS JUNIOR; PIERCE, 1996).

\section{Resistência à penetração}

A resistência do solo à penetração é apontada como um dos fatores limitantes ao desenvolvimento e estabelecimento das culturas, pois ela expressa o grau de compactação do solo; varia com o tipo de solo e com a espécie cultivada, sendo que suas causas têm sido atribuídas ao tráfego de máquinas agrícolas. Alguns parâmetros são importantes para a quantificação da resistência à penetração, tais como a densidade e o conteúdo de água do solo. A densidade apresenta uma relação direta com a resistência (BORGES et al., 1988), enquanto que o conteúdo de água influência negativamente a resistência (TORMENA; SILVA; LIBARDI, 1998).

Hatano et al. (1988) afirmam que existe uma estreita relação entre porosidade do solo e o crescimento radicular, com maior crescimento de raízes onde há maior número e continuidade de macroporos. Desta forma, o aumento da resistência mecânica do solo causa efeitos prejudiciais ao sistema radicular das culturas. Como exemplo, pode-se citar o aumento do diâmetro das raízes na camada compactada e a diminuição do diâmetro das raízes para penetrar pequenos poros, pois a resistência mecânica do solo estimula a proliferação de raízes laterais, que são mais finas (MATERECHERA et al., 1992; RUSSEL; GOSS, 1974). Assim, o aumento 
da resistência à penetração provoca modificações morfológicas e fisiológicas específicas em cada espécie ou cultivar.

Em áreas onde o sistema de plantio direto é adotado, a ausência de revolvimento tem provocado um aumento da densidade do solo que refletirá em maior resistência à penetração (HAKANSSON ; MEDVEDEV, 1995; KERTZMANN, 1996; KLEIN; LIBARDI; SILVA, 1998; SILVA; REINERT; REICHERT, 2000a, 2000b). Silva, Reichert e Reinert (2004) observaram que a distribuição da compactação do solo neste sistema ocorre de maneira sistemática, sendo maior nas laterais da lavoura, diminuindo para o centro, em função do tráfego de máquinas.

Com relação aos níveis críticos de resistência, na literatura vários níveis são adotados, conforme Ehlers et al. (1983), Nesmith (1987), Merotto Junior e Mundstock (1999) e Canarache (1990), que indicaram valores de 1,0, 2,0, 3,5 e 5,0 $\mathrm{MPa}$, respectivamente, como sendo o limite crítico de resistência à penetração de raízes para diferentes solos.

Silva, Tormena e Imhoff (2002) relatam que um valor de 2,0 MPa de resistência à penetração do solo têm sido associado a condições impeditivas para o crescimento das raízes e da parte aérea das plantas. Camargo e Alleoni (1997) admitem que quando a resistência à penetração é menor do que $1,1 \mathrm{MPa}$ não há limitação ao crescimento radicular, sendo o solo considerado como de muito baixa resistência, enquanto que para valores entre 1,0 e 2,5 $\mathrm{MPa}$, a resistência deve ser considerada baixa, ocorrendo pouca limitação ao crescimento radicular. Grant e Lafond (1993) afirmam que valores que variam de 1,5 a 3,0 MPa são admitidos como limite crítico. Tormena, Silva e Libardi (1998) afirmam que o valor de resistência do solo à penetração de 2,0 $\mathrm{MPa}$ é considerado como restritivo ao desenvolvimento das plantas. De acordo com Dexter e Watts (2000), a compactação do solo é mais prejudicial em solo seco, sendo que em condições de maior umidade pode haver crescimento radicular em valores de resistência à penetração superiores a 4,0 MPa. Assim, como há divergências na literatura quanto ao nível crítico de resistência à penetração, muitos pesquisadores, utilizam o valor de 2,0 MPa como o limite crítico (TAYLOR; ROBERTSON; PARKER, 1966).

Beulter e Centurion (2004), objetivando avaliar o efeito da compactação do solo no desenvolvimento radicular e na produtividade da soja em Latossolo Vermelho de textura média, verificaram que no maior nível de resistência à penetração (camada de 0,0 $0,20 \mathrm{~m}$ ) ocorreram mudanças na distribuição do sistema radicular e que houve aumento da espessura das raízes na camada mais compactada de $0,05-0,15$ m. Foi verificada também maior concentração de raízes finas com o aumento da resistência à penetração na camada de 0,0-0,05 $\mathrm{m}$. Ocorreu também um ligeiro espelhamento no perfil, que se iniciou a partir da resistência à penetração de 1,82 $\mathrm{MPa}$ e se tornou mais visível a partir de $3,87 \mathrm{MPa}$. Portanto, a camada compactada aumenta em profundidade no maior valor de resistência à penetração de 4,25 MPa. Foi verificado ainda, o espessamento das raízes principais a partir da resistência à penetração de $3,87 \mathrm{MPa}$ e o seu crescimento nos planos verticais de fraqueza (rachaduras), em que ocorrem espaços livres para seu desenvolvimento. Esses resultados corroboram os de Barbieri, Poli e Donzelle (1985), que mencionam que a compactação do solo não se apresenta de forma contínua ao longo de grandes extensões e que, em solos compactados, as raízes se desenvolvem através dos planos verticais de fraqueza. Tão importante quanto o desenvolvimento radicular é a determinação do valor crítico de resistência à penetração ao desenvolvimento radicular e sua relação com a produtividade de grãos. Desta forma, o autor estabeleceu para um Latossolo Roxo a equação de regressão quadrática entre a resistência à penetração e a produtividade de grãos de soja, sendo obtido o valor de resistência à penetração de 0,85 MPa como valor a partir do qual a produtividade de grãos de soja decresceu. 


\section{Considerações Finais}

A compactação do solo pelo tráfego de máquinas agrícolas tem sido uma preocupação desde o início da mecanização na agricultura brasileira, pois é um dos fatores que mais influencia a sustentabilidade dos solos agrícolas, em virtude das modificações ocasionadas em algumas propriedades físicas do solo.

A extensão e a intensidade da compactação do solo vão depender da pressão exercida pelos pontos de apoio das máquinas e equipamentos, das suas cargas, do número de vezes que trafegam no terreno, da textura e da agregação do solo. Assim, o tráfego de máquinas e equipamentos de grande porte sobre a área de cultivo pode alterar sensivelmente as características físicas do solo, principalmente quando estes estão saturados, ocasionando a formação de camadas compactadas, tanto em superfície como em subsuperfície. As principais modificações nas propriedades físicas do solo que podem ocorrer são desde aumento na densidade do solo, aumento da resistência do solo à penetração das raízes, redução da macroporosidade com conseqüente redução da condutividade e do acúmulo de água, comprometendo desta forma a infiltração de água e a penetração das raízes no perfil do solo, o qual se torna mais suscetível à erosão.

Mesmo com a adoção de práticas conservacionistas como o plantio direto, a compactação do solo continua provocando alterações nas propriedades físicas e a causa desta compactação neste sistema de cultivo é normalmente atribuída ao tráfego de máquinas agrícolas em condições de alta umidade no solo.

Com relação às máquinas e equipamentos utilizados, devemos levar em consideração alguns aspectos importantes, tais como: a) o tipo de pneu utilizado e a pressão de insuflagem, que determinarão a distribuição da pressão no solo pelas máquinas agrícolas, cujo peso determinará o total da força exercida sobre a superfície do solo; b) o tamanho da área de contato entre o pneu e o solo, que determina a distribuição da força pela área de contato.
Portanto, a utilização da mecanização na agricultura deve vir acompanhada de técnicas que possibilitem a menor alteração possível nas características físicas dos solos, permitindo a sustentabilidade dessas áreas e evitando sua degradação. Neste intuito, sugerem-se algumas práticas com a finalidade de se prevenir e/ou aliviar a compactação pelo tráfego de máquinas agrícolas:

- Diminuir a movimentação de máquinas e equipamentos pesados sobre o solo, principalmente quando este se apresentar saturado;

- Confinar a execução das operações de preparo do solo, semeadura, tratos culturais e colheita às épocas em que o solo estiver menos sensível à compactação, ou seja, com menor conteúdo de água;

- Em sistema de preparo do solo convencional, devese alternar os níveis de profundidade alcançado pelas operações de aração e gradagem, evitando a formação da camada compactada, ou retardando a sua ocorrência;

- Realizar periodicamente a descompactação do solo com auxilio de subsoladores e escarificadores, tanto em sistema de preparo mínimo do solo como em sistema de plantio direto;

- Utilizar pneus de máquinas agrícolas com carcaça flexível, baixa pressão de inflação, diâmetro largo e uma pequena largura de secção;

Com a adoção dessas técnicas por parte dos agricultores, os efeitos da compactação do solo poderão ser minimizados, melhorando assim o ambiente para desenvolvimento do sistema de raízes das culturas e possibilitando a sustentabilidade da agricultura.

\section{Referências}

ABREU, S.L. Propriedades hídricas e mecânicas afetadas por sistemas de manejo e variabilidade espacial de um Argissolo. 2000. 65p. Dissertação (Mestrado em Ciência do Solo) - Universidade Federal de Santa Maria, Santa Maria, RS. 
AGASSI, M.; MORIN, J.; SHAINBERG, I. Effect of raindrop impact energy and water salinity on infiltration rates of sodic soils. Soil Science Society of America Journal, Madison, v.49, p.186-190. 1985.

ALAKUKKU, L.; ELOMEN, P. Long-term effects of a single compaction by heavy field traffic on yeld and nitrogen uptake of annual crops. Soil and Tillage Research, Amsterdam, v.36, p.141-152, 1994.

ALBUQUERQUE, J.A.; REINERT, D.J.; FIORIN, J.E.; RUEDELL, J.; PETRERE, C.; FONTINELLI, F. Rotação de culturas e sistemas de manejo do solo: efeito sobre a forma da estrutura do solo ao final de sete anos. Revista Brasileira Ciência do Solo, Viçosa, v.19, p.115-119, 1995.

ANDREOLA, F.; COSTA, L.M.; OLSZEVSKI, N. Influência da cobertura vegetal de inverno e da adubação orgânica e, ou, mineral sobre as propriedades físicas de uma Terra Roxa Estruturada. Revista Brasileira Ciência do Solo, Viçosa, v.24, p.857-865, 2000.

ARVIDSSON, J. Subsoil compaction caused by heavy sugarbeet harvesters in southern Sweden I. Soil physical properties and crop yield in six field experiments. Soil and Tillage Research, Amsterdam, v.60, n.1/2, p.67-78, 2001.

ASSOULINE, S.; TAVARES FILHO, J.; TESSIER, D. Effects of compaction on soil physical and hydraulic properties: experimental results modeling. Soil Science Society of America Journal, Madison, v.61, p.390-398, 1997.

BAILEY, A.C.; RAPER, R.L.; JOHNSON, C.E.; BURT, E.C. An integrated approach to soil compaction prediction. Journal Agriculture Engineering Research, London, v.61, p.73-80, 1993 .

BALL, B.C.; CAMPBELL, D.J.; DOUGLAS, J.T.; HENSHALL, J.K.; O'SULLIVAN, M.F. Soil structural quality, compaction and land management. European Journal of Soil Science, Oxford, v.48, p.593-601, 1997.

BARBIERI, J.L.; POLI, D.M.; DONZELLE, J.L. Os latossolos roxos e a cana-de-açúcar. São Paulo: Coopersucar, 1985. (Boletim Técnico, n. 32)

BARBOSA, G.M.C.; TAVARES FILHO, J.; FONSECA, I.C.B. Avaliações das propriedades físicas em Latossolo Vermelho eutroférrico tratado com lodo de esgoto por dois anos consecutivos. Sanare, Curitiba, v.17, p.94-101, 2002.

BAYER, C. Dinâmica da matéria orgânica em sistemas de manejo de solos. 1996. 240p. Tese (Doutorado em Ciência do Solo) - Departamento de Solos, Universidade Federal do Rio Grande do Sul, Porto Alegre, RS.

BEARE, M.H.; BRUCE, R.R. A comparison of methods for measuring water-stable aggregates: implications for determining environmental effects on soil structure. Geoderma, Amsterdam, v.56, n.1, p.87-104, 1993.
BERTOL, I. Comprimento crítico de declive para preparos conservacionistas de solo. 1995. 185p. Tese. (Doutorado em Ciência do Solo) - Departamento de Solos, Universidade Federal do Rio Grande do Sul, Porto Alegre, RS.

BERTOL, I.; SCHICK, J.; MASSARIOL, J.M.; REIS, E.F.; DILY, L. Propriedades físicas de um cambissolo húmico álico afetadas pelo manejo do solo. Ciência Rural, Santa Maria, v.30, p.91-95, 2000.

BEULTER, A.N.; CENTURION, J.F. Compactação do solo no desenvolvimento radicular e na produtividade da soja. Pesquisa Agropecuária Brasileira, Brasília, v.39, n.6, p.581-588, 2004.

BEULTER, A.N.; SILVA, M.L.N.; CURI, N.; FERREIRA, M.M.; CRUZ, J.C.; PEREIRA FILHO, I.A. Resistência à penetração e permeabilidade de Latossolo Vermelho distrófico típico sob sistemas de manejo na região dos cerrados. Revista Brasileira Ciência do Solo, Viçosa, v.25, p.167-177, 2001.

BICKI, T.J.; SIEMENS, J.C. Crop response to wheel traffic soil compaction. Transaction of the ASAE, St. Joseph, v.34, p.909-913, 1991.

BLACK, G.R.; NELSON, W.W.; ALLMARAS, R.R. Persistense of sobsoil compaction in a mollisol. Soil Science Society of America Journal, Madison, v.40, p.943948, 1976.

BORGES, E.N.; NOVAIS, R.F.; REGAZZI, A.J.; FERNANDES, B.; BARROS, N.F. de. Respostas de variedades de soja à compactação de camadas de solo. Revista Ceres, Viçosa, v.35, n. 202, p.553-568, 1988.

BORTOLOZZO, A.R.; SANS, L.M.A. Selamento superficial e seus efeitos na taxa de infiltração: uma revisão. Revista FactuCiência, Unaí, ano 1, n.1, p.32-42, 2001.

BRUCE-OKINE, E.; LAL, R. Soil erodibility as determined by raindrop technique. Soil Science, Baltimore, v.119, n.2, p.149-157, 1975.

CAMARGO, O.A. Compactação do solo e desenvolvimento de plantas. Campinas, SP: Fundação Cargill, 1983.44p.

CAMARGO, O.A.; ALLEONI, L.R.F. Compactação do solo e o desenvolvimento das plantas. Piracicaba, SP: ESALQ, 1997. 132p.

CAMPOS, R.C.; REINERT, D.J.; NICOLODI, R.; RUEDELL, J.; PETRERE, C. Estabilidade estrutural de um Latossolo Vermelho-Escuro distrófico após sete anos de rotação de culturas e sistemas de manejo do solo. Revista Brasileira Ciência do Solo, Viçosa, v.19, p.121-126, 1995.

CANARACHE, A. Penetr - a generalized semi-empirical model estimating soil resistence to penetration. Soil and Tillage Research, Amsterdam, v.16, p.51-70, 1990. 
CANILLAS, E. C.; SALOKHE, V. M. A decision support system for compaction assessment in agricultural soils. Soil Tillage Research, Amsterdam, v.65, n.2, p.221-230, 2002.

CARPENEDO, V. Compressibilidade de solos em sistemas de manejo. 1994. 106p. Tese (Doutorado em Ciência do Solo) - Departamento de Solos, Universidade Federal do Rio Grande do Sul, Porto Alegre, RS.

CASTRO FILHO, C.; CORSINI, P.C.; SOARES, D.; POLITANO, W. Acceptance of soil and water conservation strategies and technologies in Southern Brazil. In: BAUM, E.; WOLFF, P.; ZOBISCH, M. A. (Ed.). Acceptance of soil and water conservation. Strategies and Technologies. Topics in applied resource management in the tropics. German Institute for Tropical and Subtropical Agriculture, Witzenhausen, v.3, p.341-363, 1993.

CASTRO NETO, P. Desenvolvimento e avaliação de equipamentos e metodologia para determinação de parâmetros físicos do solo relacionados a dias trabalháveis com máquinas agrícolas. 2001. 156p. Tese (Doutorado em Agronomia) - Departamento de Energia na Agricultura, Universidade Estadual de São Paulo, Botucatu, SP.

CENTURION, J.F.; CARDOSO, J.P.; NATALE, W. Efeito de formas de manejo em algumas propriedades físicas e químicas de um Latossolo Vermelho em diferentes agroecossistemas. Revista Brasileira de Engenharia Agrícola e Ambiental, Campina Grande, v.5, n.2, p.254258, 2001.

COSTA, F.S.; BAYER, C.; ALBUQUERQUE, J.A.; FONTOURA, S.M.V. Aumento de matéria orgânica num latossolo bruno em plantio direto. Ciência Rural, Santa Maria, v.34, n.2, p.587-589, 2004.

CRUZ, A. C. R.; PAULETTO, E. A.; FLORES, C. A.; SILVA, J. B. Atributos físicos e carbono orgânico de um argissolo vermelho sob sistemas de manejo. Revista Brasileira Ciência do Solo, Viçosa, v.27, p.1105-1112, 2003.

CURTIS, R.O.; POST, B.W. Estimating bulk density from organic matter content in some Vermont forest soils. Soil Scince Society America Proceedings, Madison v.28, p.285-286, 1964.

DAlla ROSA, A. Práticas mecânicas e culturais na recuperação física de solos degradados pelo cultivo no solo Santo Ângelo (Latossolo Roxo distrófico). 1981. 138p. Dissertação. (Mestrado em Ciência do Solo) - Universidade Federal do Rio Grande do Sul, Porto Alegre, RS.

DAUDA, A.; SAMARI, A. Cowpea yield response to soil compaction under trator on a sandy loam soil in the semiarid region of northern Nigeria. Soil and Tillage Research, Amsterdam, v.68, n.1, p.17-22, 2002.
DE JONG-HUGHES, J.; MONCRIEF, J.F.; VOORHEES, W.B.; SWAN, J.B. Soil compacting: causes, effects and control. Morris, Minnesota: University of Minnesota Extension Service, 2001. 15p. (Communication and Educational Technology Services)

DE MARIA, I.C.; CASTRO, O.M.; DIAS, H. S. Atributos físicos do solo e crescimento radicular de soja em Latossolo Roxo sob diferentes métodos de preparo do solo. Revista Brasileira Ciência do Solo, Viçosa, v.23, p.703-709, 1999.

DENARDIN, J.E.; KOCHHANN, R.A. Pesquisa de desenvolvimento em sistema plantio direto no Rio Grande do Sul. In: CONGRESSO BRASILEIRO DE CIÊNCIA DO SOLO, 26., 1997, Rio de Janeiro. Anais... Rio de Janeiro: Sociedade Brasileira de Ciência do Solo, 1997. 1 CD ROOM.

DERPSCH, R.; ROTH, C.; SIDIRAS, N.; KÖPKE, U. Controle de erosão no Paraná, Brasil: sistemas de cobertura do solo, plantio direto e preparo conservacionista do solo. Eschborn: Deutsche Gesellschaff für Technische Zusammenarbeit (GTZ), 1991.272p.

DEXTER, A.R.; TANNER, D.W. Time dependence of compressibility for remolded and undisturbed soils. Journal of Soil Science, London, v.25, p.153-164, 1973.

DEXTER, A.R.; WATTS, C. Tensile strength and friability. In: SMITH, K.; MULLINS, C. Soil and environmental analysis, physical methods. New York: Marcel Dekker, 2000. p.401-430.

DIAS JUNIOR, M. S. Compression of three soils under long-term tillage and wheel traffic. 1994. Thesis (Ph.D. in Crop and Soil Science) - Michigan State University, East Lansing, EUA.

DIAS JUNIOR, M. S.; PIERCE, F. J. O processo de compactação do solo e sua modelagem. Revista Brasileira de Ciência do Solo, Campinas, v.20, p.175-182, 1996.

DIAS JUNIOR, M.S.; FERREIRA, M.M.; FONSECA, S.; SILVA, A.R.; FERREIRA, D.F. Avaliação quantitativa da sustentabilidade estrutural dos solos em sistemas florestais na região de Aracruz-ES. Revista Árvore, Viçosa, v.23, n.4, p.371-380, 1999.

DIAS JUNIOR, M.S.; MIRANDA, E.E.V. Comportamento da curva de compactação de cinco solos da região de lavras (MG). Ciência Agrotécnica, Lavras, v.24, n.2, p.337$346,2000$.

DIAS JUNIOR, M.S.; PIERCE, F.J. A simple procedure for estimating preconsolidation pressure from soil compression curses. Soil Technology, Amsterdam,v.8, n.2, p.139-151, 1995.

DÜRR, C.; AUBERTOT, J. N. Emergence of seedling of sugar beet (Beta vulgaris L.) as affected by aggregate size, roughness and position of aggregates in the seedbed. Plant and Soil, The Hague, v.219, n.1/2, p.211-220, 2000. 
EHLERS, W.; KOPKE, V.; HESSE, F.; BÖHM, W. Penetration resistance and root growth of oats in tilled and untilled loess soil. Soil and Tillage Research, Amsterdam, v.3, n.2, p.261-275, 1983.

EKWUE, E. I.; STONE, R. J. Organic matter effects on strength properties of compacted agricultural soils. Transactions of the ASAE, St. Joseph, v.38, n.2, p.357-367, 1995.

Density-moisture relations of some Trinidadian soils incorporated with sewage sludge. Transaction of the ASAE, St. Joseph, v. 40, p. 317-323, 1997.

ETANA, A.; COMIA, R.A.; HAKANSSON, I. Effects of uniaxial stress on the physical properties of four Swedish soils. Soil and Tillage Research, Amsterdam, v.44, n.1, p.13-21, 1997.

FARRES, P.J.; COUSEN, S.M. An improved method of aggregate stability measurement. Earth Surface Processes and Landforms, Chichester, v.10, p.321-329, 1985.

FAUNE, A. A new conception of the plastic and liquid limits of clay. Soil and Tillage Research, Amsterdam, v.1, n.2, p.97-105, 1981.

FENNER, P.T. Relações entre tráfego, solo e desenvolvimento florestal na colheita da madeira. 1999. 135p. Tese (Tese de Livre Docência) - Universidade Estadual de São Paulo, Botucatu, SP.

FLOWERS, M.D.; LAL, R. Axle load and tillage effects on soil physical properties and soybean grain yield on a molic ochraqualf in northwest Ohio. Soil and Tillage Research, Amsterdam, v.48, p.21-35, 1998.

FULLER, L.G.; GOH, T.G. Stability-energy relationships and their application to aggregation studies. Canadian Journal of Soil Science, Ottawa, v.72, n.4, p.453-466, 1992.

GODEFROY, J.; JACQUIN, F. Relation entre la stabilité structurale des sols cultivés et les apports organiques en conditions tropicales; comparasion avec les sols forestiers. Fruits, Paris, v.30, p.595-612, 1975.

GRANT, C.A.; LAFOND, G.P. The effects of tillage systems and crop sequences on soil bulk density and penetration resistance on a clay soil in Southern Saskatchewan. Canadian Journal Soil Science, Ottawa, v.73, n.2, p.223232, 1993.

GREGORICH, E.G.; KACHANOSKI, R.G.; VORONEY, R.P. Ultrasonic dispersion of aggregates: distribution of organic matter in size fractions. Canadian Journal of Soil Science, Ottawa, v.68, n.2 p.395-403, 1988.

GUIMARÃES, C.M.; STONE, L.F.; MOREIRA, A.A.J. Compactação do solo na cultura do feijoeiro. II: efeito sobre o desenvolvimento radicular e da parte aérea. Revista Brasileira de Engenharia Agrícola e Ambiental, Campina Grande, v.6, p.213-218, 2002.
GUPTA, S.C.; ALLMARAS, R.R. Models to assess the susceptibility of soil to excessive compaction. Advances in Soil Science, New York, v.6, p.65-100, 1987.

GUPTA, S.C.; HADAS, A.; SCHAFER, R.L. Modelling soil mechanical behavior during compaction. In: LARSO, W.E; BLAKE, G.R.; ALLMARAS, R.R.; VOORHEES, W.B.; GUPTA, S.C. Mechanics and related process in structured agricultural soils. The Netherlands: Kluwer Academic Publishers, 1989. p.137-152.

GUPTA, S.C.; HADAS, A.; VOORHEES, W.B.; WOLF, D.; LARSON, W.E.; SCHNEIDER, E.C. Development of quids for estimating the ease of compaction of world soils. Bet Dagan: Research Report, Binational Agriculture Research Development, University of Minnesota, 1985. 178p.

HAJABBASI, M.A.; JALALIAN, A.; KARIMZADEH, H.R. Deforestation effects on soil physical and chemical properties. Plant and Soil, Lordegan, v.190, p.301-308, 1997.

HAKANSSON, I.; MEDVEDEV, V.W. Protection of soils from mechanical overloading by establishing limits for stresses caused by heavy vehicles. Soil and Tillage Research, Amsterdam, v.35, p.85-97, 1995.

HAKANSSON, I.; VOORHEES, W.R.; RILEY, H. Vehicle and wheel factors influencing soil compaction and crop response in different traffic regimes. Soil and Tillage Research, Amsterdam, v.11, p.239-282, 1988.

HATANO, R.; IWANAGA, K.; OKAJIMA, H.; SAKUMA, T. Relationship between the distribution of soil macropores and root elongation. Soil Science and Plant Nutrition, Tokyo, v.34, n.4, p.535-546, 1988.

HERNANI, L.C.; SALTON, J.C.; FABRÍCIO, A.C.; DEDECEK, R.; ALVES JR., M. Perdas por erosão e rendimentos de soja e de trigo em diferentes sistemas de preparo de um Latossolo Roxo de Dourados (MS). Revista Brasileira Ciência do Solo, Viçosa, v.21, p.667-676, 1997.

HILLEL, D. Environmental soil physics. New York: Academic Press, 1998. 771p.

Introduction to soil physics. San Diego: Academic Press, $1982.364 \mathrm{p}$.

HOLTZ, R.D.; KOVACS, W.D. An introduction to geotechnical engineering. Englewood: Prentice-Hall, 1981.733p.

HORN, R. Compressibility of arable land. Catena, Jerusalém, v.11, p.53-71, 1988.

The effect of static and dynamic loading on stress distribution, soil deformation and its consequences for soil erosion. In: BLUME, H.P.; FLEISCHHAUER, M.; HEBEI, T. Sustainability, environmental protection. Catena: Publ. Cremlingen In Press, 1998. 23p. 
Stress transmission and recompaction in tilled and segmently disturbed subsoils under trafficking. In: JAYAWARDANE, N.; STEWART, B.A. Subsoiling management techniques. New York: Advances in Soil Science, 1994. p.187-210.

HORN, R.; LEBERT, M. Soil compactability and compressibility. In: SOANE, B. D.; OUWERKERT, C. van. Soil compaction in crop production. Amsterdam: Elsevier, 1994.p.45-69,

HORN, R.; DOMZAL, H.; SLOWINSKA-JURKIEWICZ, A.; VAN OUWERKERK, C. Soil compaction processes and their effects on the structure of arable soils and environment. Soil and Tillage Research, Amsterdam, v.35, p.23-36, 1995.

IMHOFF, S.C. Indicadores de qualidade estrutural e trafegabilidade de Latossolos e Argissolos Vermelhos. 2002. 104p. Tese (Doutorado em Agronomia) Departamento de Solos e Nutrição de Plantas, Escola Superior de Agricultura "Luiz de Queiroz", Universidade de São Paulo, Piracicaba, SP.

ISHAQ, M.; IBRAHIM, M.; HASSAN, A.; SAEED, M.; LAL, R. Subsoil compaction effects on crop in Punjab, Pakistan: II root growth and nutrient uptake of wheat and sorghum. Soil and Tillage Research, Amsterdam, v.60, n.3/4, p.153-161, 2001.

JORGE, J.A. Compactação do solo: causas, conseqüências e maneiras de evitar a sua ocorrência. Campinas, SP: Instituto Agronômico de Campinas, 1986. (Circular Técnica)

KAY, B.D.; SILVA, A.P.; BALDOCK, J.A. Sensivity of soil structure to changes in organic carbon content: predictions using pedotransfer functions. Canadian Journal of Soil Science, Ottawa, v.77, p.655-667, 1997.

KEMPER, W.D.; CHEPIL, W.S. Size distribution of aggregates. In: BLACK, C.A. (Ed.). Methods of soil analysis. Madison: American Society of Agronomy Journal, 1965. v.1, p.499-509.

KEMPER, W.D.; ROSENAU, R.C. Aggregate stability and size distribution. In: KLUTE, A. (Ed.). Methods of soil analysis. Madison: American Society of Agronomy Journal, 1986. v.1, p.425-442.

KERTZMANN, F.F. Modificações na estrutura e no comportamento de um Latossolo Roxo provocados pela compactação. 1996. 153p. Tese (Doutorado em Geografia Física) - Faculdade de Filosofia, Letras e Ciências Humanas, Universidade de São Paulo, São Paulo, SP.

KLEIN, V.A.; BOLLER, W. Avaliação de diferentes manejos de solo e métodos de semeadura em áreas sob sistema de plantio direto. Ciência Rural, Santa Maria, v.25, n.3, p.395-398, 1995.
KLEIN, V.A.; LIBARDI, P.L.; SILVA, A.P. Resistência mecânica do solo à penetração sob diferentes condições de densidade e teor de água. Engenharia Agrícola, Jaboticabal, v.18, n.2, p.45-54, 1998.

KLUTHCOUSKI, J.; FANCELLI, A.L.; DOURADO-NETO, D.; RIBEIRO, C.M.; FERRARO, L.A. Manejo do solo e o rendimento da soja, milho, feijão e arroz em plantio direto. Scientia Agrícola, Piracicaba, v.57, n.1, p.97-104, 2000.

KOCHHANN, R.A.; DENARDIN, J.E. Comportamento das culturas de trigo, soja e milho à adubação fosfatada no sistema de plantio direto e preparo convencional. In: SEMINÁRIO INTERNACIONAL DO SISTEMA PLANTIO DIRETO, 2., 1997, Passo Fundo. Anais... Passo Fundo: EMBRAPA-CNPT, 1997. p.243-246.

KONDO, M.K. Compressibilidade de três Latossolos sob diferentes usos. 1998. 95p. Dissertação (Mestrado em Agronomia) - Departamento de Solos e Nutrição de Plantas, Universidade Federal de Lavras, Lavras, MG.

KONDO, M. K.; DIAS JUNIOR, M. S. Compressibilidade de três latossolos em função da umidade e uso. Revista Brasileira de Ciência do Solo, Viçosa, v.23, p.211-218, 1999.

KOOLEN, A.J. Mechanics of soil compaction. In: SOANE, B.D.; OUWERKERK, C. Soil compaction in crop production. Amsterdam: Elsevier, 1994. p.45-69.

LAL, R. Role of mulching techniques in tropical soil and water management. Ibadan: International Institute of Tropical Agriculture, 1974.37p. Technical Bulletin, n. 1.

LARSON, W. E.; GUPTA, S. C. Estimating critical stress in unsaturated soils from changes in pore water pressure during confined compression. Soil Science Society of America Journal, Madison, v.44, n.6, p.1127-1132, 1980.

LARSON, W.E.; GILL, W.R. Soil physical parameters for designing new tillage systems. In: NATIONAL CONSERVATION TILLAGECONFERENCE. 1973, Ankeny. Proceedings... Ankeny: Soil Conservation Society of America, 1973. p.13-22.

LAWS, J.O. Recent studies in raindrops and erosion. Agricola Engineering, v. 21, p.431-433. 1940.

LEBERT, M.; HORN, R. A method to predict the mechanical strength of agricultural soils. Soil and Tillage Research, Amsterdam, v.19, p.275-286, 1991.

LIMA, C.L.R. Compressibilidade de solos versus intensidade de tráfego em um pomar de laranja e pisoteio animal em pastagem irrigada. 2004. 70p. Tese (Doutorado em Agronomia) - Departamento de Solos e Nutrição de Plantas, Escola Superior de Agricultura "Luiz de Queiroz", Universidade de São Paulo, Piracicaba, SP. 
LINDSTROM, W.J.; SCHUMACHER, T.E.; COGO, N.P.; BLECHA, M.L. Tillage effects on water runoff and soil erosion after sod. Journal of Soil Water Conservation, Ankeny, v.53, p.59-63, 1998.

LOGSDON, S.D.; ALLMARAS, R.R.; NELSON, W.W.; VOOHEES, W.B. Persistence of subsoil compaction from heavy axle loads. Soil and Tillage Research, Amsterdam, v.23, p.95-110, 1992.

MATERECHERA, S. A.; ALSTON, A. M.; KIRBY, J. M.; DEXTER, A. R. Influence of root diameter on the penetration of seminal roots into a compacted subsoil. Plant and Soil, Dordrecht, v.144, p.297-303, 1992.

MAZURAK, A.P.; MOSHER, P.N. Detachment of soil particles in simulated rainfall. Soil Science Society of America, Madison, v.32, n.5 p.716-719, 1968.

McBRIDE, R.A. Estimation of density-moisture-stress functions from uniaxial compression of unsaturated, structured soils. Soil and Tillage Research, Amsterdam, v.13, n.4, p.383-397, 1989.

McBRIDE, R.A.; BOBER, M.L. Are-examination of alternative test procedures for soil consistency limit determination: I. A compression-based procedure. Soil Science Society of America Journal, Madison, v.53, p.178183, 1989.

McBRIDE, R.A.; WATSON, G.C. An investigation of reexpansion of unsaturated, structured soils during cycles static loading. Soil and Tillage Research, Amsterdam, v.17, n.3/4, p.241-253, 1990.

McCALLA, T.M. Water drop method of determining the stability of soil structure. Soil Science Society of America, Madison, v.7, p.209-214, 1944.

McNABB, D.H.; BOERSMA, L. Nonlinear model for compressibility of partly satured soils. Soil Science Society of America Journal, Madison, v.60, n.2, p.333341, 1996.

MEROTTO, A.J.; MUNDSTOCK, C.M. Wheat root growth as affected by soil strength. Revista Brasileira de Ciência do Solo, Viçosa, v.23, p.197-202, 1999.

MIRANDA, E.É.V. Avaliação da sustentabilidade da estrutura de um Latossolo sob cultivo de cafeeiro na região do cerrado. 2001.57p. Dissertação (Mestrado em Agronomia) - Departamento de Solos e Nutrição de Plantas, Universidade Federal de Lavras, Lavras, MG.

NESMITH, D.S. Soil compaction in double cropped wheat and soybean on Ultissol. Soil Science Society of America Journal, Madison, v.51, p.183-186, 1987.

NORTH, P.F. Towards an absolute measurement of soil structural stability using ultrasound. Journal of Soil Science, Oxford, v.27, n.4, p.451-459, 1976.
NOVAK, L.R.; MONTOVANI, E.C.; MARTYN, P.J.; FERNANDES, B. Efeito do tráfego de trator e da pressão de contato pneu/solo na compactação de um Latossolo Vermelho-Escuro Álico, em dois níveis de umidade. Pesquisa Agropecuária Brasileira, Brasília, v.27, p.15871595, 1992.

O'SULLIVAN, M.F. Uniaxial compaction effects on soil physical properties in relation to soil type and cultivation. Soil and Tillage Research, Amsterdam, v.24, n.3/4, p.257269, 1992.

OHU, J.O; AYOTAMUNO, M.B.; FOLORUNSO, O.A. Compaction characteristics of prominent agricultural soil in Borno State of Nigeria. American Society of Agricultural Engineering, St. Joseph, v.30, p.1575-1577, 1987.

OLIVEIRA, G.C.; DIAS JUNIOR, M.S.; RESK, D.V.S.; CURI, N. Alterações estruturais e comportamento compressivo de um Latossolo Vermelho distrófico argiloso sob diferentes sistemas de uso e manejo. Pesquisa Agropecuária Brasileira, Brasília, v.38, n.2,p.291-299, 2003.

OLIVEIRA, J.O.A.P.; VIDIGAL FILHO, P.S.; TORMENA, C.A.; PEQUENO, M.G.; SCAPIM, C.A.; MUNIZ, A.S.; SAGRILO, E. Influência de sistemas de preparo do solo na produtividade da mandioca (Manihot esculenta, Crantz). Revista Brasileira Ciência do Solo, Viçosa, v.25, p.443-450, 2001.

OLIVEIRA, M.; CURI, N.; FREIRE, J.C. Influência do cultivo na agregação de um podzólico vermelho-amarelo textura média/argilosa da região de Lavras, MG. Revista Brasileira de Ciência do Solo, Campinas, v.7, n.3, p.317322, 1983.

OLSON, H.J. Calculation of subsoil compaction. Soil and Tillage Research, Amsterdam, v.29, p.105-111, 1994.

PERIN, E.; CERETTA, C. A.; KLAMT, E. Tempo de uso agrícola e propriedades químicas de dois latossolos do planalto médio do Rio Grande do Sul. Revista Brasileira de Ciência do Solo, Viçosa, v.27, p.665-674, 2003.

POJASOK, T.; KAY, B.D. Assessment of a combination of wet sieving and turbidimetry to characterize the structural stability of moist aggregates. Canadian Journal of Soil Science, Ottawa, v.70, n.1, p.33-42, 1990.

POLLARD, F.; ELLIOT, J.G. The effect of soil compaction and method of fertilizer placement on the growth of barley using a concrete track technique. Journal Agriculture Engineering Research, London, v.23, p.203-216, 1978.

RADFORD, B. J.; YULE, D. F.; MCGARRY,D.; PLAYFORD, C. Crop response to applied soil compaction and to compaction repair treatment. Soil and Tillage Research, Amsterdam, v.61, n.3/4, p.155-170, 2001. 
RAGHAVAN, G.S.V.; ALVO, P.; MCKYES, E. Soil compaction in agriculture: A review toward managing the problem. Advances in Soil Science, London, v.11, p.1-36, 1990.

RAGHAVAN, G.S.V.; MICKYES, E. Physical and hydraulic characteristics in compacted clay soils. Journal of Terramechanics, Elmsford, v.19, p.235-242, 1983.

RAINE, S.R.; SO, B. An energy based parameter for the assessment of aggregate bond energy. Journal of Soil Science, Oxford, v.44, n.2, p.249-259, 1993.

REINERT, D.J. Soil structural form and stability induced by tillage in a typic Hapludalf. 1990. 128p. Tese. (Doutorado) - Michigan State University, Michigan, EUA.

RESENDE, M.; CURI, N.; REZENDE, S.B.; CORRÊA, G.F. Pedologia: base para distinção de ambientes. Viçosa: NEPUT, 1995. 304p.

RIBEIRO, M. A. V. Resposta da soja e do eucalipto a fósforo em solos de diferentes texturas, níveis de densidade e de umidade. 1999. 71p. Tese (Doutorado em Agronomia) - Departamento de Solos e Nutrição de Plantas, Universidade Federal de Lavras, Lavras, MG.

ROSOLEM, C.A.; FERNANDEZ, E.M.; ANDREOTTI; M.; CRUSCIOL, C.A.C. Crescimento radicular de plântulas de milho afetado pela resistência do solo à penetração. Pesquisa Agropecuária Brasileira, Brasília, Brasília, v.34, p.821-828, 1999.

RUSSEL, R. S.; GOSS, M. J. Physical aspects of soil fertility: the response of roots to the mechanical impedance. Netherlands Journal of Agricultural Science, Wageningen, v.22, p.305-318, 1974.

SÁNCHEZ-GIRÓN, V.; ANDREU, E.; HERNANZ, J.L. Response of five types of soil to simulated compaction in the form of confined uniaxial compression test. Soil and Tillage Research, Amsterdam, v.48, n.1/2, p.37-50, 1998.

SAXON, K.E.; McCOOL, D.K.; KENNY, J.F. Tillage and residues impacts on infiltration. In: FOK, Y. (Ed.). Infiltration principles and practices. Water Resources Research Center, Honolulu, , 1988. p.509-513

SCHAEFER, C.E.R.; SILVA, D.D.; PAIVA, K.W.N.; PRUSKI, F.F.; ALBUQUERQUE FILHO, M.R.; ALBUQUERQUE, M.A. Perdas de solo, nutrientes, matéria orgânica e efeitos microestruturais em Argissolo Vermelho-Amarelo sob chuva simulada. Pesquisa Agropecuária Brasileira, Brasília, v.37, n.5, p.669-678, 2002.

SCHOENHOLTZ, S.H.; VAN MIEGROET, H.; BURGER, J.A. A review of chemical and physical properties as indicators of forest soil quality: challenges and opportunities. Forest Ecology and Management, Wageningen, v.138, p.335-356, 2000.
SERVADIO, P.; MARSILI, A.; PAGLIAI, M.; PELLEGRINI, S.; VIGNOZZI. Effect on some clay soil qualities following the passage of rubbertracked and wheeled tractors in central Italy. Soil and Tillage Research, Amsterdam, v.61, n.3/4, p.143-155, 2001.

SEYBOLD, C.A.; HERRICK, J.E.; BREJDA, J.J. Soil resilience: a fundamental component of soil quality. Soil Science, New Brunswick, v.164, p.224-234, 1999.

SILVA, A. P.; KAY, B. D.; PERFECT, E. Characterization of the least limiting water range of soils. Soil Science Society of America Journal, Madison, v.58, p.1775-1781, 1994.

SILVA, A. P.; LIBARDI, P.L.; CAMARGO, O.A. Influência da compactação nas propriedades físicas de dois Latossolos. Revista Brasileira de Ciência do Solo, Campinas, v.10, p.91-95, 1986.

SILVA, A. P.; TORMENA, C. A.; IMHOFF, S. Intervalo hídrico ótimo. In: MORAES, M. H.; MÜLLER, M. M. L.; FOLONI, J. S. S. Qualidade física do solo: métodos de estudo sistemas de preparo e manejo do solo. Jaboticabal: FUNEP, 2002. p.1-18.

SILVA, I. F.; MIELNICZUK, J. Ação do sistema radicular de plantas na formação e estabilização de agregados do solo. Revista Brasileira Ciência do Solo, Viçosa, v.21, p.113-117, 1997.

SILVA, J. G. Ordens de gradagem e sistemas de aração do solo: desempenho operacional, alterações na camada mobilizada e respostas do feijoeiro (Phaseolus vulgaris L.). 1992. 180p. Tese (Doutorado em Agronomia), Universidade Estadual Paulista, Botucatu, SP.

SILVA, M. L .N.; CURI, N.; BLANCANEAUX, P. Sistemas de manejo e qualidade estrutural de Latossolo Roxo. Pesquisa Agropecuária Brasileira, Brasília, v.35, p.24852492, 2000.

SILVA, M. L. N.; CURI, N.; MARQUES, J.J.G.S.M.; FERREIRA, M.M; LIMA, L.A. Resistência ao salpico provocado por impacto de gotas de chuva simulada em latossolos e sua relação com características químicas e mineralógicas. Ciência e Prática, Lavras, v.19, n.2, p.348354, 1995.

SILVA, R. B.; DIAS JUNIOR, M.S.; SILVA, F. A. M.; FOLE, S. M. O tráfego de máquinas agrícolas e as propriedades físicas, hídricas e mecânicas de um latossolo dos cerrados. Revista Brasileira Ciência do Solo, Viçosa, v.27, p.973983, 2003.

SILVA, R. B.; LIMA, J.M.; DIAS JUNIOR, M.S.; SILVA, F.A.M. Influência da adição de fósforo no índice de compressão e propriedades de consistência de um Latossolo Vermelho Escuro. Revista Brasileira Ciência do Solo, Viçosa, v.25, p.261-268, 2001. 
SILVA, V. R.; REICHERT, J.M.; REINERT, D.J. Variabilidade espacial da resistência do solo à penetração em plantio direto. Ciência Rural, Santa Maria, v.34, n.2, p.399-406, 2004.

Resistência mecânica do solo à penetração influenciada pelo tráfego de uma colhedora em dois sistemas de manejo do solo. Ciência Rural, Santa Maria, v.30, n.5, p.795-801, 2000 b.

. Susceptibilidade à compactação de um Latossolo Vermelho-Escuro e de um Podzólico Vermelho-Amarelo. Revista Brasileira de Ciência do Solo, Viçosa, v.4, p.239249, 2000a.

SILVEIRA, P.M.; STONE, L.F. Sistemas de preparo do solo e rotação de culturas na produtividade de milho, soja e trigo. Revista Brasileira de Engenharia Agrícola e Ambiental, Campina Grande, v.7, n.2, p.240-244, 2003.

SINGER. M.; EWING, S. Soil quality. In: SUMNER, M.E. Handbook of soil science. Boca Raton: CRC Press, 2000. p.271-298.

SIX, J.; ELLIOT, E.T.; PAUSTIAN, K. Aggregate and organic matter dynamics under conventional and no tillage systems. Soil Science Society of America Journal, Madison, v.63, p.1350-1358, 1999.

SMITH, C.W.; JOHNSTON, M.A.; LORENTS, S. Assessing the compaction susceptibility of South African forestry soils. I. The effect of soil type, water content and applied pressure on uni-axial compaction. Soil and Tillage Research, Amsterdam, v.41, n.1/2, p.53-73, 1997.

SMITH, S.T.; STONEMAN, T.C.; MALCOLM, C.V. Cultivation and traffic hardpans in Swan Valley Vineyards. West Aust.: Agriculture Department, 1969. Technical Bulletin n. 1.

SMUCKER, A.J.M.; ERICKSON, A.E. Tillage and compactive modifications of gaseous flow and soil aeration. In: LARSON, W.E.; BLAKE, G.R.; ALLMARAS, R.R.; VOORHEES, W.B.; GUPTA, S.C. Mechanics related process in structured agricultural soils. The Netherlands: Kluwer Academic Publishers, 1989. p.205-221.

SOANE, B.D. Process of soil compaction under vehicular traffic and means of alleviating it. In: LAL, R.; SANCHEZ, P.A.; CUMMINGS, R.W. Land clearing and development in the tropics. Rotterdam: Balkema Publisher, 1986.p.265-297.

. The role of organic matter in soil compactability: a review of some practical aspects. Soil and Tillage Research, Amsterdam, v.16, n.1/2, p.179-201, 1990.

SPERA, S.T.; SANTOS, H.P.; FONTANELI, R.S.; TOMM, G.O. Efeitos de sistemas de produção de grãos envolvendo pastagens sob plantio direto nos atributos físicos de solo e na produtividade. Revista Brasileira Ciência do Solo, Viçosa, v.28, p.533-542, 2004.
STENBERG, B. Monitoring soil quality of arable land: microbiological indicators. Soil and Plant Science, v.49, n.1,p.1-24, 1999.

STONE, J.A.; LARSON, W.E. Rebound of five onedimensionally compressed unsaturated granular soils. Soil Science Society of America Journal, Madison, v.44, p.819822,1980 .

STONE, L.F.; SILVEIRA, P.M. Efeitos do sistema de preparo e da rotação de culturas na porosidade e densidade do solo. Revista Brasileira Ciência do Solo, Viçosa, v.25, p.395-401, 2001.

SWAN, J.B.; MONCRIEF, J.F.; VOOHEES, W.B. Soil compaction causes, effects, and control. St. Paul: University of Minnesota, 1987. Agriculture Bulletin, 3115.

TAVARES FILHO, J.; TESSIER, D. Influence des pratiques culturales sur le comportement et les propriétés de sols du Paraná (Brésil). Étude et Gestion des Sols, Paris, v.5, n.1,p.61-71, 1998.

TAYLOR, H. M.; BRAR, G. S. Effect of soil compaction on root development. Soil and Tillage Research, Amsterdam, v.19, p.111-119, 1991.

TAYLOR, H.M.; ROBERTSON, G.M.; PARKER, J.J. Soil strength root penetration relations for medium to coarse textured soil materials. Soil Science, New Brunswick v.102, p.18-22, 1966.

TOPP, G.C.; REYNOLDS, W.D.; COOK, F.J.; KIRBY, J.M.; CARTER, M.R. Physical attributes of soil quality. In: GREGORICH, E.G.; CARTER, M.R. Soil quality for crop production and ecosystem health. Amsterdam: Elsevier Science, 1997. p.21-58.

TORMENA, C.A.; ROLLOF, G. Dinâmica da resistência à penetração de um solo sob plantio direto. Revista Brasileira Ciência do Solo, Viçosa, v.20, p.333-339, 1996.

TORMENA, C.A.; SILVA, A.P.; LIBARDI, P.L.Caracterização do intervalo hídrico ótimo de um Latossolo Roxo sob plantio direto. Revista Brasileira de Ciência do Solo, Viçosa, v.22, p.573-581, 1998.

TORRES, E.; SARAIVA, O.F. Camadas de impedimento mecânico do solo em sistema agrícolas com soja. Londrina: EMBRAPA-CNPSoja, 1999. 58p. Circular Técnica, n. 23.

TREIN, C.R.; LEVIEN, R.; SOUZA, L.F. C. Tráfego controlado. Revista Cultivar Máquinas, n.41, p.22-25, 2005.

VIEIRA, M.J.; MUZILLI, O. Características físicas de um Latossolo Vermelho Escuro sob diferentes sistemas de manejo. Pesquisa Agropecuária Brasileira, Brasília, v.19, p.873-882, 1984. 
VOMOCIL, J.A.; FLOCKER, W.J. Effect os soil compaction on storage and movement of soil, air and water. American Society Agricultural Engineering, St. Joseph, v.4, p.242246, 1966.

VOORHEES, W.B. Soil compaction: our newest natural resource. Crops and Soils Magazine, Madison, v.29, p.13$15,1977$.

VOORHEES, W.B.; SENST, G.G.; NELSON, W.W. Compaction and soil structure modification by wheel traffic in the Northern Corn Belt. Soil Science Society of America Journal, Madison, v.42, p.344-349, 1978.

WAY, T.R.; BAILEY, A.C.; RAPER, R.L.; BURT, E.C. Tire lug height effect on soil stresses and bulk density. American Society Agricultural Engineering, St. Joseph, v.38, p.669-674, 1995.

WIERMANN, C.; WAY, T.R.; HORN, R.; BAILEY, A.C.; BURT, E.C. Effect of various dynamic loads on stress and strain behavior of a Norfolk sandy loam. Soil and Tillage Research, Amsterdam, v.50, p.127-135, 1999.

WIERMANN, C.; WERNER, D.; HORN, R.; ROSTEK, J.; WENER, B. Stress/strain processes in a structured silty loam Luvisol under different tillage treatments in Germany. Soil and Tillage Research, Amsterdam, v.53, p.117-128, 2000.
WISCHMEIER, W.H.; SMITH, D.D. Rainfall energy and its relationship to soil loss. Transactions of the ASAE, St. Joseph, v. 39, p.285-291. 1951.

WOOD, R.K.; REEDER, R.C.; MORGAN, M.T.; HOLMES, R.G. Soil physical properties as affected grain cart traffic. American Society Agricultural Engineering, St. Joseph, v.36, p.11-14, 1993.

WU,L.; FENG, G.; LETEY, J.; FERGUSON, L.; MITCHELL, J.; McCULLOUGH-SANDEN, B.; MARKEGARD, G. Soil management effects on the nonlimiting water range. Geoderma, v.114, p.401-414, 2003.

YODER, R.E. A direct method of aggregate analysis of soils and a study of the physical nature of erosion. American Society of Agronomy Journal, Madison, v.28, p.337-351, 1936.

ZHANG, H.; HARTGE, K.H.; RINGE, H. Effectiveness of organic matter incorporation in reducing soil compactability. Soil Science Society of America Journal, Madison, v.61, n.1, p.239-245, 1997. 